\title{
Eğitim Mobilyaları Standardının (TS EN 1729-1) Ergonomik Yaklaşımlara Uygunluğunun Değerlendirilmesi
}

\author{
Evaluation of the Compliance of Educational Furniture Standard (TS EN 1729-1) \\ with Ergonomic Approaches
}

Koray DEVELi (D) , Sarp Korkut SÜMER

\begin{abstract}
ÖZET
Bu çalışmada, eğitim mobilyaları standardında (TS EN 1729-1) belirtilen sınır değerlerin, ergonomik yaklaşımlar ile uyumunun belirlenmesi amaçlanmıştır. Bu amaçla, Çanakkale Onsekiz Mart Üniversitesi Ziraat Fakültesi öğrencileri üzerinde antropometrik ölçüm çalışmaları yürütülmüştür. Antropometrik veriler ve çeşitli araştırmacılar tarafından ortaya konulmuş olan ergonomik yaklaşımlar dikkate alınarak ergonomik eğitim mobilyaları boyutları belirlenmiş, standartta belirtilen değerler ile karşılaştırılmıştır. Öğrenciler için hesaplanan mobilya boyutlarının standartta belirtilen boyutlar ile tam olarak örtüşmediği ve söz konusu uygunsuzluğun \%61.90 oranında olduğu belirlenmiștir. Çalışmada ayrıca fakültede bulunan eğitim mobilyalarının ilgili standarda uygunluğu ve ergonomisi değerlendirilmiştir. Eğitim mobilyaları için yapılan değerlendirmede derslik, amfi ve çizim salonu için; ergonomik açıdan uygunluk yüzdeleri sırasıyla \%25.00 \%12.50 ve \%37.50, standarda uygunluk yüzdeleri ise sırasıyla \%61.53, \%46.15 ve \%76.92 olarak hesaplanmıştır. Bu durumun, öğrencilerin derslere motivasyonlarının yanı sıra boyun, sırt, bel ağrısı gibi kas-iskelet sistemi rahatsızlıklarına neden olabileceği ve Avrupa ülkelerindeki tüm eğitim kurumları için geçerli olan TS EN 1729-1 standardının, Türkiye'de bir yükseköğretim kurumunda öğrencilere ait antropometrik özelliklere göre belirlenen ergonomik gereklerin tamamını karşılayamadığı görülmüştür. Sonuç olarak, eğitim kurumlarında mobilyaların standarda uygunluğunun yanı sıra antropometrik özellikler ve ergonomik yaklaşımlar dikkate alınarak tasarımlanması gerektiği sonucuna varılmıștır.

Anahtar Kelimeler: Ergonomi, Antropometri, Öğrenci, Mobilya Standardı
\end{abstract}

\section{ABSTRACT}

In this study, it is aimed to determine the compatibility of the limit values specified in the education furniture standard (TS EN 1729-1) with ergonomic approaches. For this purpose, anthropometric measurement studies were carried out on students of Çanakkale Onsekiz Mart University Faculty of Agriculture. The anthropometric data and taking into consideration ergonomic approaches put forward by various researchers, the dimensions of ergonomic education furniture were determined and compared with the values specified in the standard. It has been determined that the furniture sizes calculated for students do not exactly match the dimensions specified in the standard and the incompatibility is $61.90 \%$. In addition, the suitability to the relevant standard and ergonomics of educational furniture in the faculty were evaluated. In the evaluation made for educational furniture to the classroom, amphi and drawing hall; ergonomic suitability percentages were calculated as $25 \%, 12.50 \%$ and $37.50 \%$, respectively, and suitability to the standard percentages as $61.53 \%, 46.15 \%$ and $76.92 \%$, respectively. In this case the students as well as the motivation to lessons, neck, back, waist pain and the musculoskeletal system can cause discomfort and EN 1729-1 standards which apply to all educational institutions in European countries, It was not found to meet the identified most of ergonomic values for the anthropometric characteristics of students in higher education institutions in Turkey. Therefore, it was concluded that the furniture to be used in educational institutions should be designed not only to the standard but also taking into account the anthropometric features and ergonomic approaches. Keywords: Ergonomics, Anthropometry, Student, Furniture Standard

Koray DEVELi I koraydvl@gmail.com

Dokuz Eylül Üniversitesi, Fen Bilimleri Enstitüsü, İzmir, Türkiye

Dokuz Eylul University, The Graduate School of Natural and Applied Sciences, Izmir, Turkey

Sarp Korkut SÜMER I sarpksumer@comu.edu.tr | Sorumlu Yazar/Corresponding Author

Çanakkale Onsekiz Mart Üniversitesi, Ziraat Fakültesi, Çanakkale, Türkiye

Canakkale Onsekiz Mart University, Faculty of Agriculture, Canakkale, Turkey 


\section{GİRIŞ}

Sınıf veya derslikler, eğitim ve öğretimin hayata geçirilebilmesi için farklı kişilik özeliklerine, beklentilere ve ihtiyaçlara sahip öğrencilerin hem birbirleri ile hem de materyaller ile etkileşim halinde olduğu sosyal bir ortamdır. Bu nedenle sınıfların temiz ve düzenli tutulması önem arz etmektedir. Örneğin sınıf ortamındaki nem, hava akım hızı, sıcaklık, tahta ve tebeşirlerdeki tozlar ve sınıflarda yer alan sınıf mobilyaları, öğrenciler için en önemli etmenler arasındadır. Öğrenciler fizyolojik, biyolojik, ruhsal ve zihinsel olarak gelişimlerinin en önemli dönemini sınıflardaki sıra ve masalarda geçirdikleri için özellikle sınıfların öğrencilerin bu özelliklerine uygun olarak tasarlanmaları çok önemlidir [1].

Ülkemizde, okullardaki sınıf mobilyalarının bir kısmı Alman ve İngiliz çocuklardan alınan ölçülere göre ya da herhangi bir ölçüm alınmadan tasarlanmış mobilyalardır. Öğrenci boyutları dikkate alınmadan, farklı fiziksel özelliklere sahip toplumların antropometrik ölçülerinden yararlanılarak üretilen sınıf mobilyalarının kullanışlı ve yararlı olduğu ifadesinin ne derece doğru olduğu tartışmaya açıktır. Bu nedenle dersliklerin tasarımında ulusal bir standardın oluşturularak bu standarda göre öğrencilere uygun sınıf mobilyası tasarlanması gereklidir. Öğrencilere uygun olarak düzenlenmiş derslikler, öğrencilerin vücut, sosyal, ruhsal ve bilişsel yapılarının gelişmesine önemli katkılar sağladığı gibi, öğrenmeye odaklanarak daha fazla bilgi ve beceri kazanmalarında, hatta düzenli, tertipli ve planlı olmalarında da rol oynayacaktır. Öğrencilerin fiziksel özelliklerine ve ulusal standarda yönelik yapılan çalışmalar "Ergonomi” adı verilen bilim dalı çerçevesinde yürütülmektedir.

Ergonomiye birçok bilim dalı katkıda bulunmaktadır. Bu bilim dalları arasında antropometri bilimi, insan, ortam ve makine unsurlarından en önemlisi olan insan ile ilgili özelliklerin belirlenmesi için çalışmaktadır. İnsana uygun ve ideal makine ve ortam koşullarının tasarımlanması için, antropometrik verilerden yararlanılmaktadır.

Antropometri, insan vücut boyut ölçüleri, hareketleri ve bu hareketlerin frekans ve sınırlarını inceleyen bilim dalıdır. Diş fırçalarının kıl ve sap uzunlukları, cerrahların kullandıkları neşterlerin boyutları, otomobil takım çantalarındaki aletler, elektronik aygıtlar üzerindeki düğmeler, cep telefonlarının boyutlarının belirlenmesinde antropometrik verilerden yararlanılmaktadır [2].

Ayrıca antropometrik veriler, ofislerdeki sandalye ve masaların, sınıflardaki mobilyaların tasarımında da kullanılmaktadır. Bu tasarımlar, kişilerden ölçümü alınan, diz yüksekliği, kalça diz mesafesi ve kalça genişliği gibi verilerden yararlanılarak hesaplanmaktadır. Ancak hesaplanan bu verilerin ulusal bir standart baz alınarak hesaplanması önem arz etmektedir. Çünkü standartta yer alan her bir antropometrik boyuta ait sınır değerler ve aralıklar, o toplumunda yaşayan kişilerin antropometrik ölçüleri dikkate alınarak hazırlanmaktadır. Bu nedenle bir standardın oluşturulması ve belirli periyotlarla kontrol edilerek yenilenmesi, elde edilen verilerin yapilan hesaplamalar sonucu tasarımda kullanılacak hale getirilmesi açısından çok önemlidir.

Yapılan bu hesaplamalar, örneğin boy ortalaması 1.75 $\mathrm{m}$ olan bir toplulukta standart sapma $0.10 \mathrm{~m}$ ise, bu insanların üçte ikisinin boyu 1.65 ile 1.85 arasında olduğu prensibi dikkate alınarak, standart sapma ve ortalama değerler ile belirli bir yüzdenin altında kalacak olan boy tahmini yapılabilmektedir. Diğer bir ifadeyle, tasarımlarda örneklemden elde edilen ölçülerin en küçük ve en büyük \%5’lik kısmı ile bu ölçülerin arasında yer alan \%90'lik boyutları dikkate alınmaktadır. \%5'lik değer o toplumun en küçük boyutlara sahip \%5'ini, \%95'lik değer ise o toplumun en 
büyük boyutlara sahip $\% 5$ 'ini ifade etmektedir. Şekil 1' de görüldüğü üzere $\% 90$ 'llk söz konusu popülasyon için uygun antropometrik aralığı temsil etmektedir.

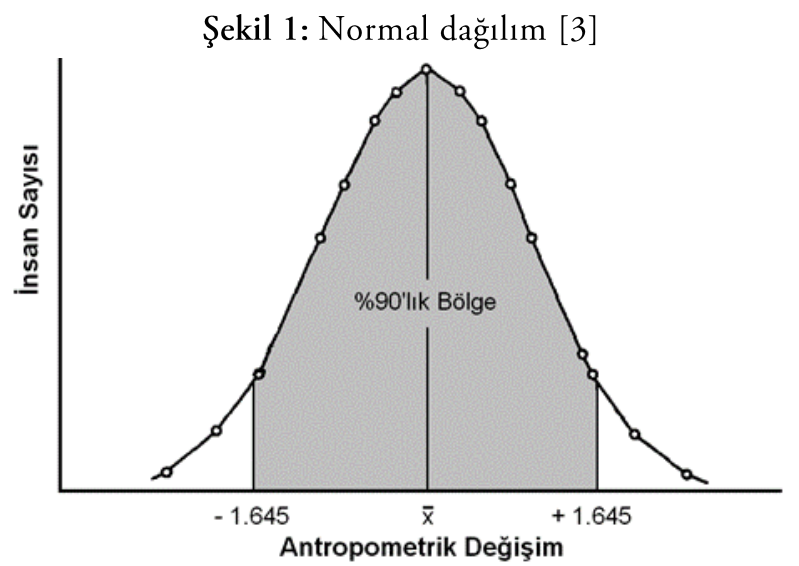

İnsanlar tarafından kullanılan bir materyalin tasarımında, materyalin kullanım şekline göre antropometrik verilerin seçimi değişiklik göstermektedir. Örneğin koltuk genişliği \%90’lık bölge içerisinde en geniş kalçalı insana (\%95) göre belirlenirken, koltuk yüksekliği $\% 90$ 'llk bölge içerisinde en küçük diz altı yüksekliği (\%5) değerine göre belirlenmektedir [3].

Sınıf mobilyalarının öğrencilere uygunluğu ve öğrenciler üzerindeki etkileri çok sayıda araştırmacının ilgisini çekmiş ve öğrencilere uygunluğunun belirlenmesi ve değerlendirilmesi üzerine çalışmalar yürütülmüştür. Kalınkara ve ark. (2011), Denizli'de Pamukkale Üniversitesi’ne bağlı çeşitli fakülte ve yüksekokullarda eğitim yapılan sınıfların tasarımına yönelik 296 kız ve erkek öğrenciden 14 antropometrik ölçü alarak antropometrik uyumunu incelemişlerdir [4]. Tunay ve Melemez (2010), yükseköğretimde kullanılan sınıf mobilyaları tasarımı için 1049 öğrenciden 13 antropometrik boyutun ölçümü alarak öğrenciler ile uygunluğunu karşılaşırmışlardır [5]. Musa ve İsmaila (2011), Nijerya'daki yükseköğretim kurumlarındaki sınıf koşullarını iyileştirmek için masa ve sıra tasarımlarını iyileştirmenin gerekli olup olmadığının belirlenmesini amaçla- yan bir çalı̧̧ma yürütmüşlerdir [6]. Gouvali ve Boudolos (2006), 6 ile 18 yaşları arasındaki çocukların okul mobilyalarının boyutlarının antropometrisi ile ilişkisini inceleyen bir çalışma yürütmüşlerdir [7]. Hoque ve ark. (2016), 1115 yaşları arasındaki 300 Bangladeşli ortaokul öğrencisinden elde edilen 15 antropometrik boyutu, mevcut sınıf mobilyalarından ölçülen 8 boyutun verileriyle karşılaştırılarak aradaki uyuşmazlığı tespit etmişlerdir [8]. Dianat ve ark. (2013), 15-18 yaşları arasındaki 978 İran lise öğrencisinin sınıf mobilya boyutları ve antropometrik özellikleri arasındaki potansiyel uyuşmazlı̆̆ değerlendirmişlerdir [9]. Panagiotopoulou ve ark. (2004), öğrencilerin antropometrik boyutlarını okul mobilyalarının boyutlarıyla karşılaştırarak, öğrencilere uygun olarak tasarlanmış olup olmadığını belirlemeyi ve öğrencileri doğru oturma pozisyonlarına teşvik etmeyi amaçlamı̧lardır [10].

Konu ile ilgili yürütülmüşş̧alışmalarda, seçilen eğitim mobilyalarının ilgili standartlara uygunluğu ya da ergonomisi değerlendirilmiştir. Ancak eğitim mobilyaları üretiminde dikkate alınması gereken standartta belirtilen değerlerin, öğrencilere uygunluğun ifadesi olan ergonomik yaklaşımları ne düzeyde karşıladığı araştırılmamıştır.

Bu çalışmada, TS EN 1729-1 (Mobilya-Eğitim Kurumları için Sandalyeler ve Masalar-Fonksiyonel Boyutlar) standardında belirtilen sınır değerlerin, ergonomik yaklaşımlar ile uyumunun belirlenmesi amaçlanmıştır. Bu amaçla, Çanakkale Onsekiz Mart Üniversitesi Ziraat Fakültesi'ndeki öğrencilerin, fakültede bulunan eğitim mobilyalarına uygunluğuna yönelik, antropometrik boyutları ölçülmüştür. Antropometrik boyutlar dikkate alınarak ergonomik mobilya boyutları hesaplanmış ve bu boyutlar standartta önerilen değerler ile karşılaştırılmıştır. Ayrıca, fakülte bünyesinde öğrenciler tarafından kullanılmakta olan eğitim mobilyalarının standarda uygunluğu ve ergonomisi değerlendirilmiştir. 


\section{YÖNTEM}

Çalışma, Çanakkale Onsekiz Mart Üniversitesi Ziraat Fakültesi’nde gerçekleştirilmiştir. Çalışmanın materyalini, TS EN 1729-1 standardı (Mobilya-Eğitim Kurumları için Sandalyeler ve Masalar- Bölüm 1- Fonksiyonel Boyutlar), Fakültede öğrenim görmekte olan öğrenciler ve eğitim mobilyaları oluşturmaktadır.

Fakültede toplam 1187 öğrenci, eğitim-öğretim faaliyetine devam etmektedir. Bu sayının 823’ünü erkek, 364’ünü ise kız öğrenciler oluşturmaktadır. Örneklemin belirlenmesinde Eşitlik 1 kullanılmış, \%95 güven düzeyi ve $\% 10$ hata payı dikkate alınmıştır $[11,12]$.

$$
n=\frac{N \cdot t^{2} \cdot p \cdot q}{d^{2}(N-1)}
$$

Eşitlikte;

$\mathrm{N}$ : Toplam birey sayısı

n: Örnekleme alınacak birey sayısı

p: Çalışmadaki yöntemin görülüşs sıklığı

$\mathrm{q}(1-\mathrm{p})$ : Çalışmadaki yöntemin görülmeyiş sıklığı

t: $\% 95$ güven düzeyinde $t$ tablosunda bulunan teorik değer d: \%10 (0.1) hata payını ifade etmektedir [13].

Çalışmadaki yöntemin görülüşs sıklığı tahmini olarak verilmektedir. Antropometrik ölçüm yöntemlerinde 2 çeşit yöntemden (direk ölçüm ve fotometrik ölçüm) direk ölçüm yöntemi bu çalışmada kullanıldığı için \%50’lik (0.5) değer verilmiştir. Görülmeyişs sıklığı da (1-p) \%50'dir. Daha önce yapılan çalışmalardan yararlanılarak güven düzeyi $\% 95$ (0.05)'e karşıllık gelen $\mathrm{t}$ tablosu değeri 1.96, hata payı $\% 10$ (0.1) olarak belirlenmiştir.

Bu yaklaşımla, 96 örneklemin Ziraat Fakültesi öğrencilerini temsil edeceği hesaplanmıştır. Bu örneklem içerisinde erkek ve kız öğrenci sayısı sırasıyla, 67 ve 29 'dur. Ancak çalışmada belirlenen örneklem sayısının üzerinde öğrenciye ulaşılabilmiş ve ölçümler gerçekleştirilmiştir. Antropomet- rik ölçümler alınan toplam 150 öğrencinin 104’ünü erkek, 46'sını kız öğrenciler oluşturmaktadır.

Öğrenciler üzerinde 5 ayakta ve 10 oturur pozisyonda toplam 15 antropometrik boyut ölçümü yapılmışırı [11, 12]. Bu boyutlar aşağıda sıralanmıştır;

- Boy,

- Ağıllık,

- Omuz yüksekliği,

- Omuz genişliği,

- Omuz-dirsek uzunluğu,

- Dirsek-parmak ucu uzunluğu,

- Dirsek yüksekliği,

- Sirt-parmak ucu mesafesi,

- Karın derinliği,

- Sirt-karın mesafesi,

- Kalça-diz mesafesi,

- Diz yüksekliği,

- Kalça-diz arkası mesafesi,

- Baldır yüksekliği.

Öğrencilerden alınan ölçümler, direkt ölçüm yöntemlerinden el aletleri ile ölçüm tekniği uygulanarak alınmıştır (Şekil 2). Ölçümler günlük/hafif kıyafet ile, oturarak ve ayakta alınan bazı ölçümler ayakkabısız alınmış olup gerekli görülen antropometrik boyutlara ayakkabı payı olarak 2 cm eklenmiştir. Gönüllülük esasına dayanılarak yapılan ölçümlerde, veriler laboratuvarda anlık olarak bilgisayarda oluşturulmuş çizelgelere kaydedilmiştir.

Standartta 4 temel mobilya çeşidi ve bu çeşitlerin antropometrik ölçüm aralıkları ve formülleri belirtilmiştir. Her mobilya çeşidi için, "Boy" ve 'Kalça-diz mesafesi”" olarak 2 kriter belirlenmiş, bu aralıklar içerisinde bulunan öğrencilerin ortalama ölçülerine göre eşitlikler kullanılmıştır. Amfi ve derslik sıraları "Eğimi $(-5)$ ve $(+7)$ derece arasında olan sandalyeler ve buna ilişkin masalar" kategorisinde, çizim salonu "Çift eğimli sandalyeler ve buna ilişkin sıralar" kategorisinde değerlendirilmiştir [14]. 
Şekil 2: Antropometrik ölçümlere ait görsel

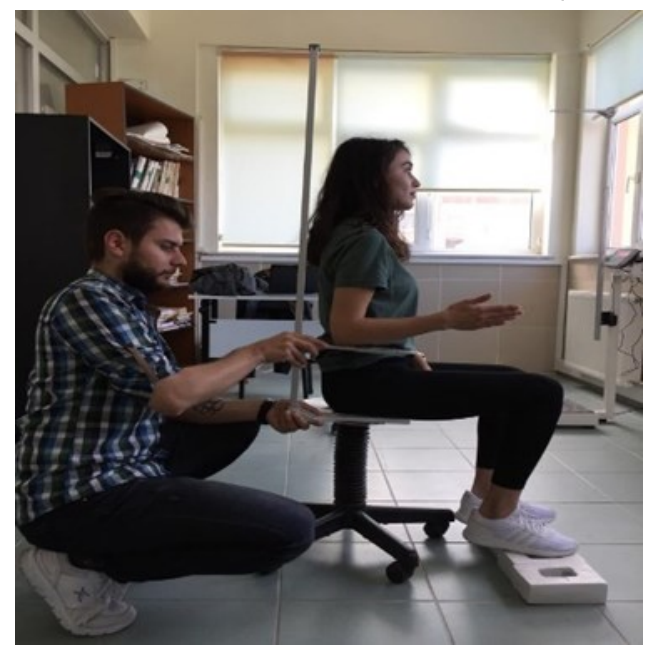

Elde edilen antropometrik ölçüler için $\% 5$ ve $\% 95$ lik değerler, minimum değer, maksimum değer, ortalama ve standart sapma değerleri hesaplanmıştır. Fakültede öğrenciler tarafından derslik, Amfi ve çizim salonunda (Şekil 3) kullanılmakta olan eğitim mobilyalarının değerlendirilmesinde, standartta belirtilen boyut özellikleri ile çeşitli araştırmacılar tarafından yürütülen çalışmalardaki ergonomik kriterler dikkate alınmıştır.

Şekil 3: Ölçümü alınan sıra ve masalar

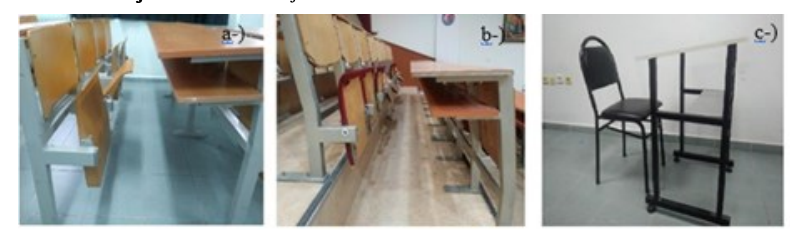

a-) derslik, b-) amfi, c-) çizim salonu sıra ve masaları

Sınıf mobilyalarından 14 boyutun ölçümü gerçekleştirilmiştir $[11,14]$. Bu boyutlardan raf yüksekliği haricindekiler, standartta belirtilen değerlendirme kriterleridir. Bu boyutlar aşağıda sıralanmıştır;

- Koltuk yüksekliği,

- Koltuk genişliği,

- Koltuk derinliği,

- Sırtlık yüksekliği,

- Sırtlık genişliği,

- Sırtlığın yatay yarıçapı,

- Koltuğun eğimi,
- Koltuk ve sırtlık arasındaki açı,

- Koltuk arkası ve S noktası arasındaki mesafe,

- Masa yüksekliği,

- Masa derinliği,

- Masa genişliği,

- Kişi başına düşen alan,

- Raf yüksekliği.

Çalışmada öncelikle seçilen mobilyaların değerlendirilmesine yönelik standart değerler ile öğrenci antropometrik boyutları ve ergonomik prensiplere göre hesaplanan değerler karşılaştırılmıştır. Ayrıca mobilyaların standart değerlere uyumu ve ergonomisi değerlendirilmiştir.

\section{BULGULAR}

Öğrencilerden alınan ölçümler, erkek (Tablo 1), kız (Tablo 2) ve toplam (Tablo 3) olarak değerlendirilmiştir. Veriler, her bir antropometrik boyuta ait \% dağılımlar (\% 5, \%50 ve \%95) ile standart sapma, minimum ve maksimum ölçümleri içerecek şekilde sunulmuştur.

Eğitim mobilyalarının fakülte öğrencileri için ergonomik boyutlarının hesaplanmasında, erkek ve kız öğrenciler için belirlenen antropometrik parametreler dikkate alınmıştır. Bazı boyutlarda kız öğrenci, bazılarında ise erkek öğrenciler için minimum ve maksimum boyutlar kullanılmıştır. İdeal boyutların hesaplanmasında genellikle \%5, \%95 ve \%50’lik değerlerden yararlanılmıştır.

Sınıf mobilyaları için antropometrik veriler dikkate alınarak ideal boyutlarının belirlenmesine yönelik yapılan yaklaşımlar ve hesaplamalar, her bir boyut için sırasıyla aşağıda açıklanmıştır;

Koltuk Yüksekliği: Yapılan bir çalışmada kız öğrencilerin \%5'lik diz altı yüksekliğine $2.5 \mathrm{~cm}$ pay eklenerek hesaplanmıştır [11]. Bu yaklaşımla, ergonomik koltuk yüksekliği değeri 47.06 olarak belirlenmiştir.

Koltuk Derinliği: Kız öğrencilerin \%5’lik kalça-baldır 
Tablo 1: Erkek öğrencilere ait antropometrik veriler

\begin{tabular}{lcccccc}
\hline Antropometrik Boyut & Min. & \%5 & Ort. (\%50) & Std. Sapma & \%95 & Max. \\
\hline Boy & 152.70 & 166.02 & 172.22 & 6.79 & 188.42 & 193.00 \\
Kilo & 48.30 & 50.17 & 77.65 & 16.65 & 105.12 & 131.40 \\
Omuz Yüksekliği (oturarak) & 53.40 & 57.53 & 60.56 & 1.84 & 63.60 & 69.50 \\
Omuz Genişliği (oturarak) & 34.70 & 40.35 & 46.53 & 3.75 & 52.72 & 56.70 \\
Omuz - Dirsek Uzunluğu (oturarak) & 30.00 & 36.06 & 36.30 & 0.49 & 37.69 & 47.50 \\
Dirsek - Parmak Ucu Uzunluğu (oturarak) & 24.90 & 41.60 & 46.85 & 3.18 & 52.10 & 58.80 \\
Dirsek Yüksekliği (oturarak) & 19.00 & 23.19 & 25.64 & 2.48 & 29.09 & 33.40 \\
Sirt- Parmak Ucu Mesafesi & 73.60 & 77.13 & 86.00 & 5.37 & 94.87 & 95.80 \\
Karın Derinliği & 13.60 & 15.68 & 21.28 & 3.39 & 26.88 & 35.70 \\
Sirt- Karın Mesafesi & 17.90 & 20.67 & 24.41 & 2.26 & 28.14 & 38.30 \\
Kalça Genişliği (oturarak) & 34.20 & 38.70 & 40.22 & 0.92 & 41.73 & 48.80 \\
Baldır Yüksekliği (oturarak) & 40.70 & 44.96 & 47.87 & 1.76 & 50.77 & 58.00 \\
Kalça-Baldır Mesafesi (oturarak) & 41.60 & 42.51 & 48.86 & 4.45 & 56.21 & 59.00 \\
Kalça- Diz Mesafesi (oturarak) & 53.00 & 55.17 & 61.35 & 3.75 & 67.54 & 67.80 \\
Diz Yüksekliği (oturarak) & 49.40 & 52.50 & 57.16 & 2.83 & 61.83 & 63.60 \\
\hline
\end{tabular}

Tablo 2: Kız öğrencilere ait antropometrik veriler

\begin{tabular}{lcccccc}
\hline Antropometrik Boyut & Min. & \%5 & Ort. (\%50) & Std. Sapma & \%95 & Max. \\
\hline Boy & 150.00 & 153.15 & 161.90 & 5.30 & 170.65 & 174.20 \\
Kilo & 39.40 & 48.79 & 61.04 & 7.45 & 73.9 & 98.50 \\
Omuz Yüksekliği (oturarak) & 54.30 & 58.34 & 59.74 & 0.85 & 61.14 & 70.20 \\
Omuz Genişliği (oturarak) & 33.20 & 36.35 & 38.80 & 1.48 & 41.25 & 47.90 \\
Omuz - Dirsek Uzunluğu (oturarak) & 30.40 & 32.18 & 33.70 & 0.92 & 35.22 & 37.50 \\
Dirsek - Parmak Ucu Uzunluğu (oturarak) & 38.10 & 40.39 & 43.08 & 1.63 & 45.76 & 47.10 \\
Dirsek Yüksekliği (oturarak) & 20.40 & 22.23 & 24.91 & 1.63 & 27.60 & 31.30 \\
Sırt- Parmak Ucu Mesafesi & 70.20 & 76.03 & 78.83 & 1.70 & 81.63 & 86.40 \\
Karın Derinliği & 13.00 & 13.84 & 18.28 & 2.69 & 25.16 & 27.50 \\
Sırt- Karın Mesafesi & 15.60 & 17.18 & 21.62 & 4.17 & 26.05 & 32.50 \\
Kalça Genişliği (oturarak) & 33.50 & 35.76 & 39.38 & 2.19 & 42.99 & 47.00 \\
Kalça-Baldır Mesafesi (oturarak) & 43.50 & 45.62 & 47.72 & 1.27 & 49.82 & 52.40 \\
Baldır Yüksekliği (oturarak) & 41.00 & 44.56 & 45.73 & 0.71 & 46.90 & 49.50 \\
Kalça- Diz Mesafesi (oturarak) & 50.70 & 51.74 & 56.49 & 3.06 & 61.53 & 63.10 \\
Diz Yüksekliği (oturarak) & 46.60 & 47.04 & 52.06 & 3.04 & 57.08 & 58.70 \\
\hline
\end{tabular}

Tablo 3: Erkek ve kadın öğrencilerin ölçülerinin toplamına ait antropometrik veriler

\begin{tabular}{lcccccc}
\hline Antropometrik Boyut & Min. & \%5 & Ort. (\%50) & Std. Sapma & \%95 & Max. \\
\hline Boy & 150.00 & 152.33 & 161.35 & 12.23 & 181.53 & 193.00 \\
Kilo & 39.40 & 50.57 & 67.08 & 10.01 & 83.58 & 131.40 \\
Omuz Yüksekliği (oturarak) & 51.30 & 54.53 & 56.40 & 1.13 & 58.27 & 69.50 \\
Omuz Genişliği (oturarak) & 34.70 & 42.39 & 43.45 & 2.05 & 44.50 & 56.70 \\
Omuz - Dirsek Uzunluğu (oturarak) & 30.00 & 33.13 & 34.65 & 0.92 & 39.90 & 47.50 \\
Dirsek - Parmak Ucu Uzunluğu (oturarak) & 24.90 & 40.97 & 44.00 & 1.84 & 47.03 & 58.80 \\
Dirsek Yüksekliği (oturarak) & 16.00 & 16.82 & 21.00 & 3.74 & 27.18 & 31.30 \\
Sırt- Parmak Ucu Mesafesi & 70.20 & 75.07 & 83.70 & 5.23 & 92.33 & 95.80 \\
Sırt-Karın Mesafesi & 15.60 & 16.99 & 24.00 & 1.41 & 31.33 & 41.30 \\
Karın Derinliği & 13.00 & 15.86 & 22.75 & 1.34 & 29.63 & 38.70 \\
Kalça Genişliği (oturarak) & 33.50 & 38.47 & 38.70 & 0.14 & 38.93 & 48.80 \\
Kalça-Baldır Mesafesi (oturarak) & 42.60 & 43.28 & 46.20 & 1.77 & 52.50 & 60.00 \\
Baldır Yüksekliği (oturarak) & 37.00 & 37.90 & 42.00 & 1.06 & 46.08 & 57.90 \\
Kalça- Diz Mesafesi (oturarak) & 51.00 & 52.65 & 57.55 & 2.97 & 65.37 & 65.80 \\
Diz Yüksekliği (oturarak) & 46.60 & 51.15 & 51.50 & 0.21 & 56.40 & 61.60 \\
\hline
\end{tabular}


mesafesinden $5 \mathrm{~cm}$ daha kısa olması önerilmiştir [11]. Ergonomik değer $40.62 \mathrm{~cm}$ olarak hesaplanmıștır.

Koltuk Genişliği: Yapılan bir çalışmada kız öğrencilerdeki \%95'lik kalça genişliğine $10 \mathrm{~cm}$ esneklik payı eklenmiştir [12]. Bu yaklaşımla, ergonomik değer $52.99 \mathrm{~cm}$ olarak hesaplanmıştır.

Sırtlık Yüksekliği: Üst kenar yüksekliği için erkek öğrencilerin \%95'lik kürek kemiği altı yüksekliği, alt kenar için kadınlarda \%5'lik bel kemiği yüksekliği sınır değerler olarak belirlenmektedir [11]. Ancak çalışmada bu antropometrik boyutların ölçümleri alınmadığı için ergonomik değer hesaplanmamıştır.
Sırtlık Genişliği: Erkek öğrencilerin omuz genişliğinin \%95'lik değerine $10 \mathrm{~cm}$ omuzun hareket etme payı eklenmiştir [11]. Bu yaklaşımla, ergonomik değer $62.72 \mathrm{~cm}$ olarak hesaplanmıştır.

Masa Yüksekliği: Kız öğrencilerin diz altı yüksekliğinin \%5'lik değerine dirsek yüksekliğinin \%50'lik değeri, 2.5 cm pay ve serbestlik payı $5 \mathrm{~cm}$ ilave edilerek hesaplanmıştır [1]. Bu yaklaşım temel alınarak ergonomik değer $78.10 \mathrm{~cm}$ olarak hesaplanmıştır.

Masa Derinliği: Erkek öğrencilerin \%50’lik dirsek parmak ucu mesafesi olarak belirlenmiştir [12]. Ergonomik değer $46.85 \mathrm{~cm}$ olarak hesaplanmıştır.

Tablo 4: Dersliklerdeki mobilya boyutlarının TSE standardı ve ergonomik değerler ile karşılaştırılması

\begin{tabular}{lccc}
\hline Ölçülen Boyutlar & Mevcut (cm) & TSE Standardı (cm) & Ergonomik Değer (cm) \\
\hline Koltuk Yüksekliği * & 43.90 & $45-47$ & 47.06 \\
Koltuk Derinliği & 42.60 & $39.5-44.5$ & 40.62 \\
Koltuk Genişliği & 39.10 & 38 (min.) & 52.99 \\
Sırtlık Yüksekliği * & 28.70 & $19-24$ & - \\
Sırtlık Genişliği & 43.90 & $33(\mathrm{~min})$. & 62.72 \\
Sırtlığın Yatay Yarıçapı * & 22.50 & 30 (min.) & $\cdot$ \\
Tek Eğimli Koltuğun Eğimi & -1.1 & $(-5)-(+7)$ & $\cdot$ \\
Koltuk ve Sırtlık Arasındaki Açı & $95.4^{\circ}$ & $95^{\circ}-110^{\circ}$ &. \\
Koltuk Arkası ile S Noktası Arasındaki Mesafe & 0 & 5 (max.) & 78.10 \\
Masa Yüksekliği & 73.30 & $74-78$ & $46, .5$ \\
Masa Derinliği* & 43.40 & 50 (min.) & 62.72 \\
Masa Genişliği * & 5100 & 60 (min.) & $\cdot$ \\
Kişi Başına Düşen Alan & $021 \mathrm{~m}^{2}$ & $0.15 \mathrm{~m}^{2}$ (min.) & 66.33 \\
Raf Yüksekliği & 61.00 & - &
\end{tabular}

$\left({ }^{*}\right)$ : TSE Standardına uygun olmayan ölçüm değeri

Tablo 5: Amfideki mobilya boyutlarının TSE standardı ve ergonomik değerler ile karşılaştırılması

\begin{tabular}{lccc}
\hline Ölçülen boyutlar & Mevcut (cm) & TSE Standart (cm) & Ergonomik Değer (cm) \\
\hline Koltuk Yüksekliği * & 52.10 & $45-47$ & 47.06 \\
Koltuk Derinliği & 40.70 & $39.5-44.5$ & 40.62 \\
Koltuk Genişliği & 41.10 & 38 (min.) & 52.99 \\
Sırtlık Yüksekliği * & 25.90 & $19-24$ & - \\
Sırtlık Genişliği * & 43.10 & 33 (min.) & 62.72 \\
Sırtlığın Yatay Yarıçapı & 37.10 & 30 (min.) & $\cdot$ \\
Tek Eğimli Koltuğun Eğimi & $-3.3^{\circ}$ & $\left(-5^{\circ}\right)-\left(+7^{\circ}\right)$ &. \\
Koltuk ve Sırtlık Arasındaki Açı & $96.3^{\circ}$ & $95^{\circ}-110^{\circ}$ &. \\
Koltuk Arkası ile S Noktası Arasındaki Mesafe & 0 & 5 (max.) & 78.10 \\
Masa Yüksekliği * & 69.90 & $74-78$ & 46.85 \\
Masa Derinliği* & 39.20 & 50 (min.) & 62.72 \\
Masa Genişliği* & 51.20 & 60 (min.) &. \\
Kişi Başına Düşen Alan * & $0.14 \mathrm{~m}^{2}$ & $0.15 \mathrm{~m}^{2}$ (min.) & 66.33 \\
Raf Yüksekliği & 58.00 & - &
\end{tabular}

$\left({ }^{*}\right)$ : TSE Standardına uygun olmayan ölçüm değeri 
Tablo 6: Çizim salonundaki mobilya boyutlarının TSE standardı ve ergonomik değerler ile karşılaştırılması

\begin{tabular}{lccc}
\hline Ölçülen Boyutlar & Mevcut (cm) & TSE Standart (cm) & Ergonomik Değer (cm) \\
\hline Koltuk Yüksekliği & 48.30 & $39.96-59.96$ & 47.06 \\
Koltuk Derinliği * $_{\text {Koltuk Genişliği * }}$ & 35.60 & $39.5-44.5$ & 40.62 \\
Sırtlık Yüksekliği & 36.20 & 42 (min.) & 52.99 \\
Sırtlık Genişliği & 23.50 & $19-24$ & - \\
Sırtlığın Yatay Yarıçapı * & 37.60 & 33 (min.) & 62.72 \\
Çift Eğimli Koltuğun Ön Kısmının Eğimi & 22.50 & 30 (min.) & - \\
Çift Eğimli Koltuğun Arka Kısmının Eğimi & 2.70 & $15^{\circ}$ (max.) & $0^{\circ}-\left(-5^{\circ}\right)$ \\
Koltuk ve Sırtlık Arasındaki Açı * & -4.5 & $95^{\circ} / 110^{\circ}$ & - \\
Koltuk Arkası ile S Noktası Arasındaki Mesafe & $89.6^{\circ}$ & 5 (max.) & 78.10 \\
Masa Yüksekliği & 2.36 & $58.3-98.3$ & 46.85 \\
Masa Derinliği & 74.60 & 50 (min.) & 62.72 \\
Masa Genişliği & 50.60 & 60 (min.) & - \\
Kişi Başına Düşen Alan & 69.40 & $0.15 m^{2}$ (min.) & 66.33 \\
Raf Yüksekliği & $0.3 m^{2}$ & - &
\end{tabular}

$\left({ }^{*}\right)$ : TSE Standardına uygun olmayan ölçüm değeri

Masa Genişliği: Sırtlık genişliği ile aynı değerde olmalıdır [11]. Ergonomik değer $62.72 \mathrm{~cm}$ olarak belirlenmiştir.

Raf Yüksekliği: Erkek öğrencilerdeki diz yüksekliğinin \%95'lik değerine ayakkabı $(2,5 \mathrm{~cm})$ payı ve serbestlik payı $(2 \mathrm{~cm})$ eklenerek hesaplanır [11]. Ergonomik değer 66.33 $\mathrm{cm}$ olarak hesaplanmıştır.

Değerlendirilen eğitim mobilyaları için; ölçülen değerler, standartta belirtilen sınır değerler ve hesaplanan ergonomik değerler, derslik, amfi ve çizim salonu için sırasıyla Tablo 4, Tablo 5 ve Tablo 6'da verilmiştir.

Derslik, amfi ve çizim salonu için ölçülen, standartta belirtilen ve hesaplanan tüm veriler incelendiğinde, her bir mobilya için standartta belirtilen 7 boyut ergonomik değerler ile karşılaştırılmıştır. Derslik, amfi ve çizim salonu bu değerlerin hesaplanan ergonomik değerler ile uygunluk oranları sırasıla; \%28.58 \%28.58 ve \%42.85 olarak hesaplanmıştır (Şekil 4). Diğer bir ifadeyle, öğrenciler için hesaplanan mobilya boyutlarının standartta belirtilen boyutlar ile tam olarak örtüşmediği ve söz konusu uygunsuzluğun ortalama \%61.90 oranında olduğu belirlenmiştir.
Şekil 4: Standart ve ergonomik uygunluk oranları

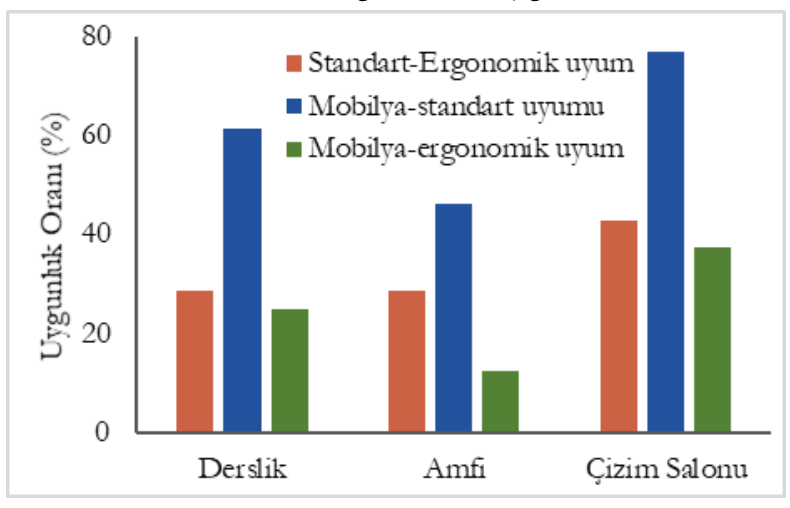

Derslik, amfi ve çizim salonu için TS EN 1729-1 standardına uygunluk oranları sırasıyla \%61.53, \%46.15 ve \% 76.92 olarak belirlenmiştir. Mobilyaların hesaplanan ergonomik değerlere uygunluğunun ise sirasıyla \%25.00 \% 12.50 ve $\% 37.50$ oranlarında olduğu bulunmuştur (Şekil 4).

\section{TARTIŞMA}

Çalışmada, bir Avrupa standardı olan ve Türkiye’yi de kapsayan TS EN 1729-1 standardındaki sınır değerler ve ergonomik değerler arasında önemli oranlarda uyumsuzluk tespit edilmiştir. Eğitim mobilyalarının ergonomisi için bazı önemli görülen antropometrik boyutlar için, bu çalışmadan elde edilen sonuçlar ile diğer çalışmaların sonuçları 
karşılaştırılmıştır.

Boy uzunluğu; Dizdar ve Okçu (2007) tarafindan kadınlar için $161.50 \mathrm{~cm}$, erkekler için $172.77 \mathrm{~cm}$ [15], Kahya ve ark. (2018) tarafından kadınlar için $163.91 \mathrm{~cm}$, erkekler için $176.40 \mathrm{~cm}$ [11], Akın ve ark. (2014) tarafından kadınlar için $160.50 \mathrm{~cm}$ erkekler için $176.30 \mathrm{~cm}$ [1], Kalınkara ve ark. (2011) tarafından kadınlar için $156 \mathrm{~cm}$, erkekler için $169 \mathrm{~cm}$ [4] olarak saptanmıştır. Boy uzunluğu bu çalışmada kadınlar için $161,90 \mathrm{~cm}$, erkekler için $172,22 \mathrm{~cm}$ olarak ölçülmüştür. Çalışmalar yıllar, yaşanılan bölgeye göre olan farklılıkları net olarak göstermektedir.

Baldır yüksekliği; Kahya ve ark. (2018) tarafından kadınlar için $45.28 \mathrm{~cm}$, erkekler için $48.25 \mathrm{~cm}$ [11], Musa ve İsmaila (2011) tarafından kadınlar için $38.51 \mathrm{~cm}$, erkekler için $42.87 \mathrm{~cm}$ [6], Hoque vd. (2016) tarafından kadınlar için $40.34 \mathrm{~cm}$ erkekler için $44.38 \mathrm{~cm}$ [8] olarak ölçülmüştür. Bu çalışmada kadınlar için $45.73 \mathrm{~cm}$, erkekler için $47.87 \mathrm{~cm}$ olarak hesaplanmıştır. Farklı ülkeler ve topluluklar için belirlenen ideal koltuk yükseklikleri tasarımlarının antropometrik özelliklerine göre farklılık gösterebileceği açıkça görülmektedir.

Sınıflardaki mobilya boyutları, öğrencilerin antropometrik ölçüleri ile karşılaştırıldığında, bazı önemli farklılıklar dikkat çekmektedir. Bu farkların yanı sıra çözüm için öneriler de getirilmiştir.

Derslik; Standart ve ergonomik kriter için belirtilen 7 parametre baz alındığında, 5 'inde ergonomik açıdan uygunsuzluk tespit edilmiş olup, özellikle koltuk genişliği ve sırtlık genişliği için standart ve ergonomik değer için belirtilen minimum değerler arasında (sırasıyla $14.99 \mathrm{~cm}$ ve $29.72 \mathrm{~cm}$ ) önemli bir uygunsuzluk saptanmıştır. Bu durum, standart değerlerin ergonomik açıdan çalışmanın materyalini oluşturan öğrenciler için doğru sonuçları yansıtmadığına işaret etmektedir.
Sınıf mobilyaları ile karşılaştırıldığında, en belirgin fark koltuk genişliğinde görülmektedir. Koltuk genişliği standarda uygun olmamakla beraber, 13.89 cm'lik bir fark ile ergonomik sınırın altında kalmıştır. Bu nedenle kalça genişliği fazla olan öğrenciler için mevcut sıranın çok dar olması öğrenciyi rahatsız edebilecektir.

Sırtlık genişliği, minimum değerin üzerinde olduğu için standarda uygundur. Ancak ergonomik değer $(62.72 \mathrm{~cm})$ ile ölçülen değer $(37.60 \mathrm{~cm})$ arasında $24.62 \mathrm{~cm}$ lik bir fark bulunması ergonomik açıdan yetersiz olduğunu göstermekle birlikte, standart ve hesaplanan ergonomik değer arasındaki fark net bir şekilde görülebilmektedir. Bu fark öğrencilere uygun sınıf mobilyası tasarımında standardın tek başına yeterli olmadığını göstermektedir.

Masa yüksekliğinin, standartta belirtilen alt ve üst sınırlar arasında olduğu tespit edilmiştir. Ancak ölçülen değer ile ergonomik değer arasında 7.80 cm'lik bir fark bulunmaktadır. Masa yüksekliğinin ergonomik değerden fazla olmasının, kısa boylu öğrencilerin yazı yazma esnasında kolunu kaldırmaları nedeniyle daha fazla statik gerilmelere, az olması halinde ise uzun boylu öğrencilerin öne eğilerek bel ağrısı gibi kas iskelet sistemi rahatsızlıklarına neden olabileceği öngörülmüştür.

Masa genişliği $9 \mathrm{~cm}$ lik bir fark ile standarttaki en küçük sınırın altında kalmaktadır. Ergonomik değerin de $11.72 \mathrm{~cm}$ altında kalması, omuz genişliği yüksek öğrencilerin yazı yazma esnasında rahat bir postürde olamayacakları nedeniyle rahat bir çalışma alanı sağlanamayacağını göstermektedir.

Dersliklerdeki 4'er kişilik sıralar ve masaların zemine ve birbirine monteli olması sebebiyle sıra ve masaların hesaplanan ergonomik değerlere göre yenilenmesinin gerektiği ortaya çıkmaktadır.

Amfi; Standartta yer alan parametrelerdeki sınır değer- 
ler ile ergonomik değer arasındaki uygunsuzluk oranları, derslikler ile aynı sonuçları yansıtmaktadır. Derslik ve çizim salonu mobilyaları ile karşılaştırıldığında, TS EN-1729 -1 standardına ve hesaplanan ergonomik değere göre uygunluk oranı en düşük mobilyaların amfide olduğu belirlenmiştir.

Koltuk yüksekliğinin $5.04 \mathrm{~cm}$ lik bir fark ile ergonomik değerin (47.06) üstünde olduğu, TSE standardında belirtilen aralığın dışında kaldığı için standarda uygun olmadığı tespit edilmiştir. Bu durumun öğrencilerin ayaklarının zemin ile temas etmemesinden dolayı diz arkasındaki bölgede statik zorlanmalar oluşturacağı ve öğrenciye rahatsızlık hissi vereceği öngörülmüştür.

Kişi başına düşen alanın $\left(0.14 \mathrm{~m}^{2}\right)$ standartta belirtilen en küçük alanın $\left(0.15 \mathrm{~m}^{2}\right)$ altında kalması, öğrencilerin dar olan kişisel alanlarından rahatsızlık duyabileceği ve dikkat ve konsantrasyon konusunda sorun yaşayabilecekleri olası bir durumdur.

Raf yüksekliğinin $(58 \mathrm{~cm})$ ergonomik değerin (66.33 $\mathrm{cm})$ altında kalması, öğrencilerin ayaklarını masaların altındaki ayaklığa koyduğu esnada rahatsızlık hissedebileceği ve düşük raf yüksekliğinin öğrencilerin diz yüksekliğinden dolayı masaya uzak kalmasına sebep olabileceği, bu nedenlerle öğrenciler için ergonomik bir tasarım olamadığı belirlenmiştir.

Amfideki sıra ve masalar zemine montelidir ve en uygun çözüm amfideki mobilyaların ergonomik değerler baz alınarak yenilenmesi olarak görülmektedir.

Çizim Salonu; Standart ve ergonomik kriter için belirtilen 7 parametre baz alındığında, 3’ünde ergonomik açıdan uygunsuzluk tespit edilmiş, bu oran \%42.85 olarak hesaplanmıştır. Derslikler için hesaplanan orandan daha az uygunsuzluk bulunmaktadır, ancak koltuk genişliği ve sırtlık genişliği için standartta yer alan değerler ve ergonomik değer arasındaki farklar ile benzer sonuçlar belirlenmiştir. Sınıf mobilyaları ile karşılaştırıldığında, TS EN-1729-1 standardına ve hesaplanan ergonomik değere göre uygunluk oranı yüzde olarak en yüksek sınıf olarak belirlenmiştir.

Çizim salonundaki koltuk ve sırtlık arasındaki açının $\left(89.6^{\circ}\right)$ standartta belirtilen aralığın $\left(95^{\circ}-110^{\circ}\right)$ altında olmasının, öğrencilerin ders dinleme ve dinlenme esnasında dik postürü bozarak kamburlaşmaya sebep olabileceği belirlenmiştir.

Sıralardaki sırtlık ve koltuk arasındaki açının standarda uygun hale getirilmesi ve masa altındaki rafın $11 \mathrm{~cm}$ yukarı kaldırılarak sıra ve masaların yeniden düzenlenmesi gerektiği sonucuna varılmıştır.

Üç mobilya çeşidi için ayrı ayrı açıklanan farklılıklar dikkate alındığında, standardın Türkiye’de seçilen bir eğitim kurumundaki öğrencileri kapsaması konusunda sapmalar içerdiği görülmüştür. Diğer bir ifadeyle, standartta belirtilen aralıklar ve belirtilen sınır değerlerin çoğunluğunun ideal ve ergonomik değerler ile örtüşmemesi ve tasarımlarda standarda uyumun yeterliliği üzerinde soru işareti oluşturmaktadır. Ayrıca fakültede mevcut sınıf mobilyalarının, standartta belirtilen değerler ve hesaplanan ergonomik değerler ile uygunluk oranlarının yeterli olmadığı belirlenmiştir.

Çalışma ortamlarının insan antropometrik ölçülerine uygun olarak tasarımının, iş verimi ve üretim maliyetleri üzerinde önemli düzeylerde olumlu etkilere sahip olduğu, çok sayıda araştırmacı tarafından ortaya konulmuştur; Bir çağrı merkezinde İş istasyonlarının kullanıcıların antropometrik özelliklerine göre yeniden tasarlanması ile (ayarlanabilir sandalyeler, yüksekliği ayarlanabilir masalar, ergonomik ara yüzler vb.) iş veriminde artışların gerçekleştiği ve firmanın 3 yılda 1 milyon dolar tasarruf ettiği rapor edilmiştir [16]. Çok sayıda bilgisayar operatörünün çalıştı̆̆1 
bir firmada; monitör yükselticileri, ayarlanabilir sandalye kullanımları ile ilgili konularda müdahalelerde bulunulmuştur ve sonuç olarak, tekrarlayan hareket sendromu vakalarının 49'dan 28'e düştüğü, tıbbi masrafların 60.000 \$ azaldığı bildirilmiştir [17]. Bilgisayar operatörlerinin çalışma ortamlarının insan antropometrisine uygun tasarımı ile, etkin çalışma süresinin \%100 artırıldığı belirtilmiş, iki yıl sonunda ise bu sayede, maliyetten yapilan tasarrufun 400.000 \$’n üzerinde olduğu rapor edilmiştir [18]. Askeri çalışma ortamlarında mobilyaların işin ihtiyacına göre yeniden tasarlanması ve kullanıma sunulması için 54,509\$ masraf yapıldığı, sonuç olarak verimliliğin \%20.6 oranında arttığı ve bir yılda $56.914 \$$ tasarruf yapıldığı belirtilmiştir. [19]. Bir sigorta şirketinde, yeni mobilya alımı ile çalışma ortamının yeniden düzenlenmesi için bir iş istasyonu başına $1.877 \$$ harcama yapıldığı, bu düzenlemenin iş verimini $\% 5.5$ oranında artırdığı ve $979 \$$ düzeyinde kişi başı yıllık tasarruf ile yapılan geri kazanımın 23 ay oluğu rapor edilmiştir [19].

Görüldüğü gibi, çalışma ortamlarının, insan antropometrik özellikleri dikkate alınarak yeniden düzenlenmesinin bir mali bedeli bulunmaktadır. Ancak bu giderler, çalışmaların daha ergonomik ortamlarda yapılmasıyla verim artışları ile meslek hastalıkları ve kaza oranlarında önemli düzeylerde azalmalar sayesinde, makul sürelerde geri kazanılmaktadır.

\section{SONUÇ}

Belirtilen bu farklardan yola çıkılarak, TS EN 1729-1 standardına bağlı kalınarak tasarımlanan sınıf mobilyalarının ergonomik açıdan yeterli olamayacağı, bu nedenle standardın yanı sıra ergonomik yaklaşımların da temel alınarak tasarımların yapılması gerektiği ya da Türk öğrencilerin antropometrisini kapsayacak şekilde revize edilmesi gerektiği sonucuna varılmıştır. Ayrıca öğrencilerin derslere motivasyonlarının yanı sıra boyun, sırt, bel ağrısı ve sakatlıklara neden olabileceği göz önüne alınarak, sadece sınıf mobilyalarının değil tüm okul yapı ve donanımlarının eğitim kurumları tarafından incelenip, öğrencilerin antropometrisine uygun olmayan sıraların ve masaların sınıflardan kaldırılarak öğrencilerin antropometrik verilerine uygun yeni mobilyalar ile değiştirilmesi için adımlar atılması ve belirli periyotlarda benzer çalışmaların tekrarlanarak sınıf mobilyalarının öğrencilere uygunluğunun kontrolünün yapılması gerektiği tespit edilmiştir. Öğrencilerin iyi bir eğitim görerek, kaliteli ve sağlıklı yetişmeleri bir ulusun geleceğe yaptığı en büyük yatırım olacaktır.

\section{KAYNAKÇA}

[1] Akın, G., Gültekin, T., Bektaş, Y., Önal, S., \& Tuncel, E. (2014). Üniversite Öğrencileri İçin Sıra Tasarımı. Ankara Üniversitesi Dil ve Tarih-Coğrafya Fakültesi Dergisi, 54(1), 269-286.

[2] Bridger, R. (2003). Introduction to Ergonomics, 2, 58-87. London: Taylor and Francis Group. [Adobe Acrobat ReaderSürümü].

[3] Sabancl, A., \& Sümer, S. K. (2015). Ergonomi (3.bs.). Ankara: Nobel Akademik Yayıncılık.

[4] Kalınkara, V., Çolakoğlu, H. E., Erturan, G., \& Güngör, H. (2011). Yükseköğrenim Yapılarında Eğitim Donanımı Tasarımına Yönelik Antropometrik Ölçülerin Belirlenmesi. Verimlilik Dergisi, 4 ,77-90.

[5] Tunay, M., \& Melemez, K. (2010). An Analysis of Biomechanical and Anthropometric Parameters on Classroom Furniture Design. African Journal of Biotechnology, 7(8), 1081-1086.

[6] Musa, A. I., \& Ismaila, S. O. (2011). Student Anthropometric Data and Furniture Mismatches in Selected İnstitutions in Abeokuta, Ogun State, Nigeria. Theoretical Issues in Ergonomics Science,15(2), 205213.

[7] Gouvali, M. K., \& Boudolos, K. (2006). Match Between School Furniture Dimensions and Children's Anthropometry. Applied Ergonomics, 37(6), 765-773.

[8] Hoque, A. S. M., Parvez, M. S., Akram, W., \& Uddin, H. (2016). Ergonomic Design of Classroom Furniture for High School Students of Bangladesh. 
SSRG International Journal of Industrial Engineering, 3(2), 1-7.

[9] Dianat, I., Karimi, M. A., Hashemi, A. A., \& Bahrampour, S. (2013). Classroom Furniture and Anthropometric Characteristics of İranian High School Students: Proposed Dimensions Based On Anthropometric Data. Applied Ergonomics, 44(1), 101-108.

[10] Panagiotopoulou, G., Christoulas, K., Papanckolaou, A., \& Mandroukas, K. (2004). Classroom Furniture Dimensions and Anthropometric Measures in Primary School. Applied Ergonomics, 35(2), 121-128.

[11] Kahya, E., Ünlüer, G., Güzeldal, Z., \& Demirci, Z. Ö. (2018). Bir Yükseköğretim Kurumunda Öğrenci Sıralarının Uygunluğunun Analizi. Ergonomics, 1(2), 59-77.

[12] Elibol, G. C., Kılıç, Y., Ulupınar, M., \& Burdurlu, E. (2005). 12-15 Yaşlarındaki Öğrencilerin Antropometrik Ölçülerinin Belirlenmesi ve Okul Mobilyalarına Uyarlanması. 11.Ulusal Ergonomi Kongresi, 7582, İstanbul Teknik Üniversitesi, İstanbul, Türkiye.

[13] Yazıcıoğlu, Y., ve Erdoğan, S. (2014). Spss uygulama1 bilimsel araştırma yöntemleri. (3.bs.). Ankara: Detay Yayıncilik.

[14] TS EN 1729-1. (2016). Mobilya-Eğitim Kurumları İçin Sandalyeler ve Masalar- Bölüm 1- Fonksiyonel Boyutlar [Türk Standardları Enstitüsü].

[15] Dizdar, E. N., \& Okçu, O. (2007). Yüksek Öğrenim Öğrencileri Antropometrik Boyutlarının Tespiti ile Sira ve Masa Boyutlarına Uygulanması. 13.Ulusal Ergonomi Kongresi, 1-9, Erciyes Üniversitesi, Kayseri.

[16] Fryer, B. \& Ignatius, E. (1994). The high cost of keyboard injuries: Blue Cross addresses repetitive strain injuries. PC World, 12(3), 45.

[17] Tadano, P. (1990). A safety/ prevention program for VDT operators: One company's approach. Journal of Hand Therapy, 3(2) 64-71.

[18] Bradley, W. (1996). Management and Prevention of on the Job Injuries, AAOHN Journal, 44(8), 402405.

[19] Steven S., Marvin, D. \& Michael, S. (1990). Promoting Health and Productivity in the Computerized Office: Models of Successful Ergonomic Interventions. Taylor and Francis, London. 